(2) Open Access Full Text Article

LETTER

\title{
Mild cognitive decline in type 2 diabetes mellitus patients - risk factors and pathogenesis: role of DPP4 activity and future possible therapeutic
}

\section{targets}

This article was published in the following Dove Medical Press journal:

Neuropsychiatric Disease and Treatment

\author{
Owais Gul' \\ Saqib Gul2 \\ 'Department of Medicine, Dow \\ Medical College, Dow University of \\ Health Sciences, Karachi, Pakistan; \\ ${ }^{2}$ Department of Medicine, Hamdard \\ University, Karachi, Pakistan
}

Correspondence: Owais Gul Department of Medicine, Dow Medical College, Dow University of Health Sciences, Flat A-303, Lateef Square, Block 16, Federal B Area, Karachi 75950, Pakistan Tel +92346 39l 8294 Email owaisgul96@yahoo.com

\section{Dear editor}

We read with great interest, the recently published article "Risk factors for developing dementia in type 2 diabetes mellitus patients with mild cognitive impairment" by Albai et al. ${ }^{1}$ The article provided a great insight into evaluating the prevalence of mild cognitive impairment (MCI) in patients with type 2 diabetes (T2DM) and highlighted the risk factors for conversion of MCI to dementia. We would like to add some knowledge of the mechanisms and pathogenesis of the development of MCI in T2DM patients and a guide to possible future therapeutic developments.

The study included a total of 207 patients with T2DM aging between 33 and 81 years. Scoring with the Mini-Mental State Examination test was mainly used for the diagnosis of dementia; however, imaging modalities (computed tomography and magnetic resonance imaging) and some other neuropsychiatric testing also provided support to the study. According to the study, MCI was found to be more prevalent among old aged patients and factors such as duration of diabetes and body fat amounts were notably associated with increased risk of MCI. Factors such as increased glucose and serum low-density lipoprotein levels, previous stroke history, and presence of cardiovascular disease were also found to be associated with conversion of MCI to full blown dementia. ${ }^{1}$

Several factors such as the role of chronic hyperglycemia in endorsing the development of cerebral microvascular disease, inflammation and oxidation stress have been implicated in brain injury leading to cognitive decline. T2DM patients are especially at risk because of high levels of glucose and inflammatory markers such as IL-6 and CRP. Moreover, an increased level of dipeptidyl peptidase (DPP4) in T2DM was found for the first time to be associated independently with MCI in elderly patients according to one study. The exact mechanism was thought to be the linkage between high DPP4 levels and the development of inflammation and oxidative stress. The study concluded by imparting a great concern to DPP4 activity both as a biological marker and a future therapeutic target. ${ }^{2}$ Another study evaluated the role of increased DPP4 and decreased brain-derived neurotrophic factor (BDNF) levels with MCI development and found higher odds ratio for MCI in elderly T2DM patients with high DBR (ratio of DPP4 to BDNF). ${ }^{3}$

DPP4 inhibitors have now been used commonly in the treatment of T2DM due to their role in countering peripheral insulin resistance and safety profile; however, no study on humans has yet depicted the role of DPP4 inhibitors in managing cognitive 
impairment in T2DM. ${ }^{2}$ A study conducted in 2013 on highfat diet-induced insulin-resistant mice showed the positive impact of DPP4 inhibitors in decreasing brain oxidative stress, reducing hippocampal mitochondrial dysfunction, and improving learning behaviors. ${ }^{4}$ In 2015 , another study on type 2 diabetic mice demonstrated the effect of DPP4 inhibition in alleviating oxidative stress and ameliorating cognitive dysfunction. ${ }^{5}$

Although enough knowledge has been attained in terms of risk factors and pathogenesis of MCI development in T2DM, the lack of enough studies regarding the drug modalities to counter this cognitive decline is an issue that needs to be addressed. As trials on mice have given us some positive results, we call for studies on humans to assess and clarify the role of these therapeutic targets in future.

\section{Disclosure}

The authors report no conflicts of interest in this communication.

\section{References}

1. Albai O, Frandes M, Timar R, Roman D, Timar B. Risk factors for developing dementia in type 2 diabetes mellitus patients with mild cognitive impairment. Neuropsychiatr Dis Treat. 2019;15:167-175.

2. Zheng T, Qin L, Chen B, et al. Association of plasma DPP4 activity with mild cognitive impairment in elderly patients with type 2 diabetes: results from the GDMD study in China. Diabetes Care. 2016;39(9):1594-1601.

3. Zheng T, Liu H, Qin L, et al. Oxidative stress-mediated influence of plasma DPP4 activity to BDNF ratio on mild cognitive impairment in elderly type 2 diabetic patients: results from the GDMD study in China. Metabolism. 2018;87:105-112.

4. Pintana H, Apaijai N, Chattipakorn N, Chattipakorn SC. DPP-4 inhibitors improve cognition and brain mitochondrial function of insulin-resistant rats. $J$ Endocrinol. 2013;218(1):1-11.

5. Ma M, Hasegawa Y, Koibuchi N, et al. DPP-4 inhibition with linagliptin ameliorates cognitive impairment and brain atrophy induced by transient cerebral ischemia in type 2 diabetic mice. Cardiovasc Diabetol. 2015; 14(1):54.

Dove Medical Press encourages responsible, free and frank academic debate. The content of the Neuropsychiatric Disease and Treatment 'letters to the editor' section does not necessarily represent the views of Dove Medical Press, its officers, agents, employees, related entities or the Neuropsychiatric Disease and Treatment editors. While all reasonable steps have been taken to confirm the content of each letter, Dove Medical Press accepts no liability in respect of the content of any letter, nor is it responsible for the content and accuracy of any letter to the editor.

\section{Publish your work in this journal}

Neuropsychiatric Disease and Treatment is an international, peerreviewed journal of clinical therapeutics and pharmacology focusing on concise rapid reporting of clinical or pre-clinical studies on a range of neuropsychiatric and neurological disorders. This journal is indexed on PubMed Central, the 'PsycINFO' database and CAS, and is the official journal of The International Neuropsychiatric Association (INA). The manuscript management system is completely online and includes a very quick and fair peer-review system, which is all easy to use. Visit http://www.dovepress.com/testimonials.php to read real quotes from published authors. 